\title{
Analisis Jalur dan Aplikasinya dalam Menentukan Faktor yang Mempengaruhi Derajat Kesehatan Balita di Sulawesi Selatan
}

\author{
Wahida Sanusi $^{1, \text { a) }}$, Sukarna ${ }^{1, \text { b) }}$, dan Elma Selviana Darwis ${ }^{1, c)}$ \\ ${ }^{1}$ Jurusan Matematika FMIPA Universitas Negeri Makassar, 90224 \\ ${ }^{a)}$ wahidah.sanusi@unm.ac.id \\ b)sukarna@unm.ac.id \\ c)elmaselviana1803@gmail.com
}

\begin{abstract}
Abstrak.Penelitian ini bertujuan untuk mengaplikasikan analisis jalur dan untuk mengetahui seberapabesarfaktor-faktor yang berpengaruhterhadapderajat kesehatan balita Di Sulawesi Selatan baiksecara pengaruh langsung maupun secara pengaruh tidak langsung Menganalisis model dan menginterpretasikan hasil. Data yang digunakan adalah data jumlah rekapitulasi derajat kesehatan balita di Provinsi Sulawesi Selatan tahun 2019. Variabel yang digunakan adalah Jumlahibuhamil 20-30 tahun $\left(X_{1}\right)$, Jumlahbalita yang mendapatkan ASI full 6 bulandari ibu yang tidak bekerja $\left(X_{2}\right)$, Kelainandalamkandungan ( $\left.X_{3}\right)$,Bayi yang terdampakgiziburuk pada ibuhamil yang usia 30-35 tahun $\left(Y_{1}\right)$, dan Bayi yang meninggaldalamkandungan $\left(Y_{2}\right)$. Penelitian ini menggunakan model dua persamaan jalur (two equation paths). Penelitian ini dimulai dari merumuskan persamaan model struktural, menghitung koefisien jalur secara simultan dan secara parsial, melakukan simulasi model menggunakan softwere SPSS 22, memaknai dan menyimpulkan. Hasil penelitian diperoleh model dua persamaan struktural;taraf signifikan (a)untuk hasil simulasi sebesar 5\% atau 0,05; menjelaskan bahwa setiap model sub-struktur yang diuji secara simultan dan secara parsial memiliki pengaruh yang positif dan signifikan terhadapderajat kesehatan balita Di Sulawesi Selatan.
\end{abstract}

Kata kunci: Analisis Jalur, two equation paths, direct effect, inderect effect

\begin{abstract}
This study aims to apply path analysis and to determine how much the factors that influence the health status of children under five in South Sulawesi, both directly (direct effect) and indirectly (inderect effect). Analyze models and interpret the results. The data used is the data on the recapitulation of the health status of children under five in South Sulawesi Province in 2019. The variables used are the number of pregnant women 20-30 years $\left(X_{1}\right)$, the number of children under five who received full 6months of breastfeeding from mothers who do not work $\left(X_{2}\right)$, in the womb $\left(X_{3}\right)$, babies who are affected by malnutrition in pregnant women aged 30-35 years $\left(Y_{1}\right)$, and babies who die in the womb $\left(Y_{2}\right)$. This study uses a two equation path model. This research starts from formulating structural model equations, calculating path coefficients simultaneously and partially, performing model simulations using SPSS 22 software, interpreting and concluding. The results of the study obtained two structural equation models; the significant level $(\alpha)$ for the simulation results is $5 \%$ or 0.05; explained that each sub-structure model tested simultaneously and partially had a positive and significant effect on the health status of children under five in South Sulawesi.
\end{abstract}

Keywords: Path Analysis, two equation paths, direct effect, indirect effect 


\section{PENDAHULUAN}

Teknik analisis jalur adalah salah satu teknik analisis statistik yang digunakan di dalam penelitian kuantitatif. Analisis jalur biasanya menggunakan istilah pengaruh langsung dan pengaruh tidak langsung, dikarenakan ada variabel perantara / interverning / variabel mediasi.Analisis jalur merupakan bentuk terapan, dari analisis multiregresi yang membantu memudahkan pengujian hipotesis dari hubungan-hubungan antar variabel yang cukup rumit. Dalam analisis jalur, korelasi antar variabel dihubungkan dengan parameter dari model yang dinyatakan dengan diagram jalur, (kuncoro dan riduan, 2007). Analisis jalur digunakan untuk melukiskan dan menguji model hubungan antar variabel yang berbentuk sebab akibat (Sugiyono, 2009). Analisis jalur memiliki kedekatan dengan regresi berganda, sehingga regresi berganda adalah bentuk khusus analisis jalur. Teknik ini dikenal sebagai model sebab-akibat (causing modeling), (Sarwono, 2007).

Penelitian ini menggunakan metode analisis jalur pada derajat kesehatan balita di sulawesi selatan. Khususnya untuk mengetahui berapa besar pengaruh langsung maupun pengaruh tidak langsung faktor yang mempengaruhi derajat kesehatan balita di Sulawesi Selatan.Menurut teori Hendrik L Blum menjelaskan indikator Derajat kesehatan balita antara lain:

a. Jumlah ibu hamil 20-35 tahun

Usia mungkin tidak menjadi masalah ketika kesehatannya terjaga. Namun, pada umumnya semakin tua usia wanita saat hamil, semakin meningkat risiko pada kesehatan dirinya dan kehamilannya.

b. Jumlah bayi yang mendapatkan ASI full 6 bulandariibu yang tidakbekerja

Pemberian ASI akan sangat optimal bila diberikan secara eksklusif selama 6 bulan pertama kehidupan anak setelah itu bayi harus dikenalkan kepada makanan padat pertamanya dan bantuan susu formula.

c. Kelainan dalam kandungan

Pertolongan ibu dan anak di indonesia. Departemen kesehatan melakukan strategi agar semua asuhan antenatal dan sekitar $60 \%$ dari keseluruhan persalinan dilayani oleh tenaga kesehatan yang terlatih. Strategi ini dilaksanakan untuk dapat mengenali dan menanggulangi gangguan kehamilan dan persalinan sedini mungkin.

d. Bayi yang terdampakgiziburuk pada ibuhamil yang usia 30-35 tahun

Gizi buruk adalah suatu kondisi dimana seseorang dinyatakan kekurangan zat gizi, atau dengan ungkapan lain status gizinya berada di bawah standar rata-rata

e. Bayi yang meninggaldalamkandungan

Angka Kematian Balita adalah jumlah kematian anak berusia 0-4 tahun selamasatu tahun tertentu per-1000 anak umur yang sama pada pertengahan tahun itu (termasuk kematian bayi) menggabungkan tingkat permasalahn kesehatan anakdan faktor-faktor lain yang berpengaruh terhadap kesehatan anak balita seperti gizi, sanitasi, penyakit menular dan kecelakaan.

\section{METODE PENELITIAN}

Data yang digunakan dalam penelitian ini adalah data sekunder, yaitu data pada tahun 2019 tentang faktor yang mempengaruhi dan indikator-indikator yang terkait pada derajat kesehatan balita di Sulawesi Selatan. Penelitian ini menggunakan model dua persamaan jalur (two equation paths model) yang mempunyai dua persamaan struktural, yaitu:

$\mathrm{Y} 1=\rho_{\mathrm{y} 1 .} \mathrm{X}_{1}+\rho_{\mathrm{y} 1 .} \mathrm{X}_{2}+\rho_{\mathrm{y} 1 .} \mathrm{X}_{3}+\varepsilon_{\mathrm{y} 1} \ldots \ldots \ldots \ldots \ldots . . .$. Model sub I

$\mathrm{Y} 2=\rho_{\mathrm{y} 2} \mathrm{X}_{1}+\rho_{\mathrm{y} 2 .} \mathrm{X}_{2}+\rho_{\mathrm{y} 2 .} \mathrm{X}_{3}+\rho_{\mathrm{y} 2 .} \mathrm{Y}_{1}+\varepsilon_{\mathrm{y} 2} \ldots \ldots \ldots \ldots . .$. Model sub II 


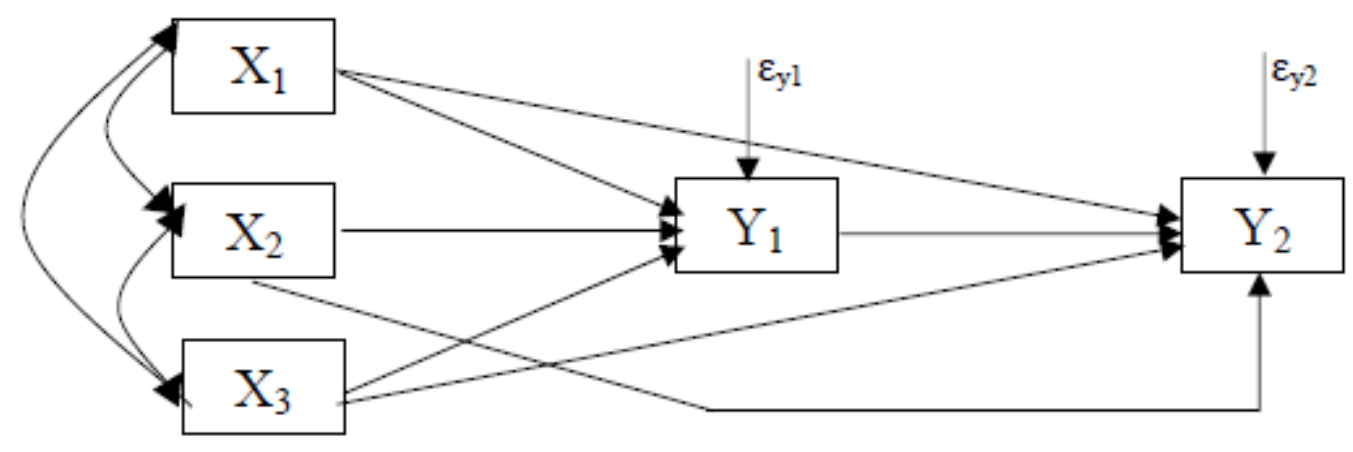

GAMBAR 1.Model Awal Analisis Jalur

Keterangan :

$\mathrm{X}_{1}=$ Jumlahibuhamil 20-35 tahun

$\mathrm{X}_{2}=$ Jumlahbayi yang mendapatkan ASI full 6 bulandariibu yang tidakbekerja

$\mathrm{X}_{3}=$ Kelainandalamkandungan

$\mathrm{Y}_{1}=$ Bayi yang terdampakgiziburuk pada ibuhamil yang usia 30-35 tahun

$\mathrm{Y}_{2}=$ Bayi yang meninggaldalamkandungan

\section{Langkah - langkah Penelitian:}

(1). Merumuskan persamaan model struktural yang mencerminkan hipotesis lengkap dengan persamaan strukturalnya

(2). Menghitung koefisien jalur yang didasarkan pada koefisien regresi untuk setiap persamaan model yang telah dirumuskan

(3). Menghitung koefisien jalur secara simultan (keseluruhan) dan secara individu

(4). Menganalisis data yang diperoleh dari hasil penelitian dengan analisis jalur menggunakan Softwere SPSS versi 22

(5). Memaknai dan menyimpulkan

\section{HASIL DAN PEMBAHASAN}

Berdasarkan metode penelitian dan data yang diperoleh, maka yang harus dilakukan adalah menganalisis data yang sudah ada dengan menggunakan software SPSS versi 22 pada taraf signifikan $(\alpha)$ sebesar $5 \%$ atau 0,05 .

\section{Pengujian model sub I}

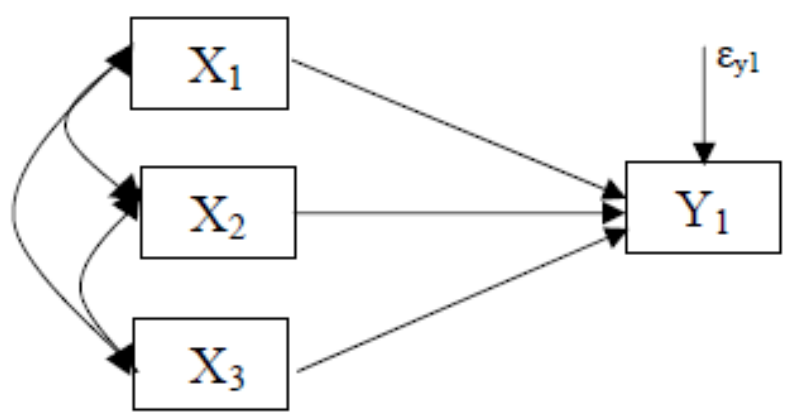

GAMBAR 2. Model diagram jalur sub I 
TABEL 1. Model Rekapitulasi (Model Summary) dua persamaan struktural

Model Summary

\begin{tabular}{lcccc}
\hline Model & $\mathbf{R}$ & R Square & $\begin{array}{c}\text { Adjusted R } \\
\text { Square }\end{array}$ & $\begin{array}{c}\text { Std. Error of the } \\
\text { Estimate }\end{array}$ \\
\hline 1 & $.778^{\mathrm{a}}$ & .605 & .546 & 22.26952 \\
\hline
\end{tabular}

Tabel R-square menghasilkan $R_{y 1(x 1, x 2, x 3)}^{2}=0,605$ atau 60,5 \%. Untuk mengukur kesalahan residulnya digunakan rumus $\varepsilon_{y 1}=\sqrt{1-R_{y 1(x 1, x 2, x 3)}^{2}}=\sqrt{1-0,605}=\sqrt{0,395}=0,628$ Sehingga diperoleh pengaruh erornya $\varepsilon_{\mathrm{yl}}=0,628$ atau $62,8 \%$.

TABEL 2.Uji F ( Anova ) model sub I

\begin{tabular}{|c|c|c|c|c|c|c|}
\hline \multicolumn{7}{|c|}{ ANOVA $^{a}$} \\
\hline \multicolumn{2}{|c|}{$\begin{array}{l}\text { Model } \\
\text { Squares } \\
\end{array}$} & Sum of & Df & $\begin{array}{l}\text { Mean } \\
\text { Square }\end{array}$ & $\mathbf{F}$ & Sig. \\
\hline 1 & Regression & 15184.998 & 3 & 5061.666 & 10.206 & $.000^{\mathrm{b}}$ \\
\hline & Residual & 9918.627 & 20 & 495.931 & & \\
\hline & Total & 25103.625 & 23 & & & \\
\hline
\end{tabular}

a. Dependent Variable: Bayi yang terdampak gizi buruk pada ibu hamil yang usia 30-35 tahun (Y1)

b. Predictors: (Constant), Kelainan dalam kandungan (X3), Jumlah bayi yang mendapatkan ASI full 6 bulan dari ibu yang tidak bekerja (X2), Jumlah ibu hamil 20-35 tahun (X1)

a. Pengujian secara simultan (keseluruhan)

Hipotesis uji :

$\mathrm{H}_{0}=$ Tidak Signifikan

$\mathrm{H}_{\mathrm{a}}=$ Signifikansi

Hasil uji : Nilai uji anova F sebesar 10.206 terlihat bahwa tabel sig sebesar 0.000 (nilai sig0.000 <0.05) menunjukkan model regresi dapat digunakan secara bersama-sama artinya $\mathrm{H}_{0}$ ditolak dan $\mathrm{H}_{\mathrm{a}}$ diterima.

TABEL 3. Uji T (Parsial) Model Sub I

Coefficients $^{\mathrm{a}}$

\begin{tabular}{|c|c|c|c|c|c|c|}
\hline \multirow{2}{*}{\multicolumn{2}{|c|}{ Model }} & \multirow{2}{*}{\multicolumn{2}{|c|}{ Unstandardized }} & \multirow{3}{*}{$\begin{array}{c}\text { Standardized } \\
\text { Coefficients } \\
\text { Beta }\end{array}$} & \multirow[b]{3}{*}{$\mathbf{T}$} & \multirow[b]{3}{*}{ Sig. } \\
\hline & & & & & & \\
\hline & & B & Std. Error & & & \\
\hline$\overline{1}$ & (Constant) & 79.782 & 11.561 & & 6.901 & .000 \\
\hline & $\begin{array}{l}\text { Jumlah ibu hamil 20-35 } \\
\text { tahun } \\
\text { (X1) }\end{array}$ & -.002 & .001 & -.737 & -1.852 & .079 \\
\hline & $\begin{array}{l}\text { Jumlah bayi yang } \\
\text { mendapatkan ASI full } 6 \\
\text { Bulan dari ibu yang }\end{array}$ & .053 & .021 & .366 & 2.541 & .019 \\
\hline
\end{tabular}


Tidak bekerja (X2)

Kelainan dalam

.008

.003

$1.249 \quad 3.121$

.005

(X3)

a. Dependent Variable: Bayi yang terdampakgiziburuk pada ibuhamil yang usia 30-35 tahun (Y1)

b. Pengujian secara parsial ( individu )

Hipotesis uji :

$\mathrm{H} 0=$ Tidak Signifikan

Ha $=$ Signifikansi

Hasil uji :

a) Dari tabel sig.X1 terhadap Y1sebesar 0.079. Nilai taraf sig 0.05 ( $0.079>0.05)$ maka H0 diterima dan Ha ditolak, artinya koefisien analisis jalurnya tidaksignifikan. Besarnya pengaruh X1 terhadap Y1 sebesar 0.737.

b) Dari tabel sig. $X_{2}$ terhadap $Y_{1}$ sebesar 0.019. Nilaitaraf sig 0.05 ( $\left.0.019>0.05\right)$ maka $\mathrm{H}_{0}$ ditolak dan $\mathrm{H}_{\mathrm{a}}$ diterima, artinya koefisien analisis jalurnya signifikan. Besarnya pengaruh $\mathrm{X}_{2}$ terhadap $\mathrm{Y}_{1}$ sebesar 0.366.

c) Dari tabelsig. $X_{1}$ terhadap $Y_{1}$ sebesar 0.005. Nilai taraf sig 0.05 ( $\left.0.005>0.05\right)$ maka $\mathrm{H}_{0}$ ditolak dan $\mathrm{H}_{\mathrm{a}}$ diterima, artinya koefisien analisis jalurnya signifikan. Besarnya pengaruh $\mathrm{X}_{3}$ terhadap $\mathrm{Y}_{1}$ sebesar 1.249.

\section{Pengujian model sub II}

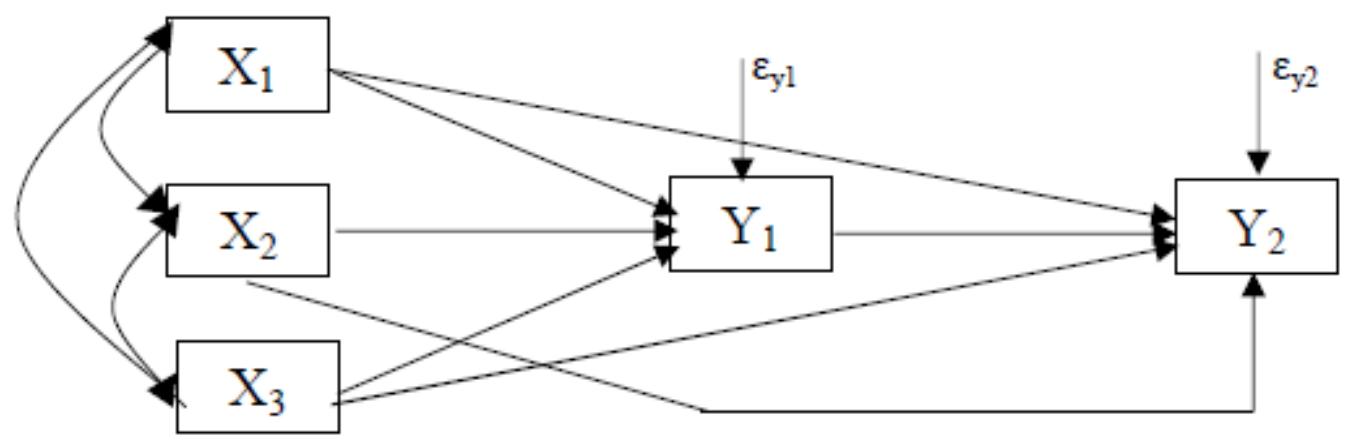

GAMBAR 3.Model Diagram Jalur Sub II

TABEL 4. Model Rekapitulasi (Model Summary) dua persamaan struktural

Model Summary

\begin{tabular}{rlrrr}
\hline Model & R & R Square & \multicolumn{1}{c}{$\begin{array}{c}\text { Adjusted R } \\
\text { Square }\end{array}$} & \multicolumn{1}{c}{$\begin{array}{c}\text { St Error of the } \\
\text { Estimate }\end{array}$} \\
\hline 1 & $.725^{\mathrm{a}}$ & .526 & .426 & 12.30869
\end{tabular}

a. Predictors: (Constant), Bayi yang terdampak gizi buruk pada ibu hamilyang usia 30-35 tahun (Y1), Jumlah ibu hamil 20-35 tahun (X1), Jumlah bayi yang mendapatkan ASI full 6 bulan dari ibu yang tidak bekerja (X2), Kelainan dalam kandungan (X3)

Tabel R-squaremenghasilkan $R_{y 2(x 1, x 2, x 3, y 1)}^{2}=0,526$ atau 52,6\%. Untuk mengukur kesalahan residulnya digunakan rumus $\varepsilon_{y 2}=\sqrt{1-R_{y 2(x 1, x 2, x 3, y 1)}^{2}}=\sqrt{1-0,526}=$ 
$\sqrt{0,474}=0,688$. Sehingga diperoleh pengaruh erornya $\varepsilon_{\mathrm{y} 1}=0,688$ atau $68,8 \%$.

Tabel 5. Uji F ( Anova ) Model Sub II

\begin{tabular}{lrrrrrr}
\multicolumn{7}{c}{ ANOVA $^{\mathbf{a}}$} \\
Model & & Sum of Squares & \multicolumn{1}{c}{ Df } & $\begin{array}{c}\text { Mean } \\
\text { Square }\end{array}$ & F & Sig. \\
\hline 1 & Regression & 3192.384 & 4 & 798.096 & 5.268 & $.005^{\mathrm{b}}$ \\
& Residual & 2878.575 & 19 & 151.504 & & \\
& Total & 6070.958 & 23 & & &
\end{tabular}

a. Dependent Variable: Bayi yang meninggal dalam kandungan (Y2)

b. Predictors: (Constant), Bayi yang terdampak gizi buruk pada ibuhamil yang usia 30-35 tahun(Y1), Jumlah ibu hamil 20-35 tahun (X1), Jumlah bayi yang mendapatkan ASI full 6 bulan dari ibuyang tidak bekerja (X2), Kelainan dalam kandungan (X3)

a. Pengujian secara simultan ( keseluruhan )

Hipotesis uji :

$\mathrm{H}_{0}=$ Tidak Signifikan

$\mathrm{H}_{\mathrm{a}}=$ Signifikansi

Hasil uji : Nilai uji anova atau F sebesar 5.268 terlihat bahwa nilai sig sebesar 0.005 (nilai sig $0.005<0.05$ ) menunjukkan model regresi dapat digunakan secara bersama-sama, artinya $\mathrm{H}_{0}$ ditolak dan $\mathrm{H}_{\mathrm{a}}$ diterima.

Tabel 6.Uji T (Parsial) Model Sub II

\begin{tabular}{|c|c|c|c|c|c|c|}
\hline \multirow{2}{*}{ Mode } & & \multicolumn{2}{|c|}{ Unstandarized Coefficientsi } & \multicolumn{3}{|l|}{$\begin{array}{l}\text { Standardized } \\
\text { Coefficients }\end{array}$} \\
\hline & & B & Std. Error & Beta & $\mathrm{T}$ & Sig. \\
\hline \multirow[t]{5}{*}{1} & (Constant) & 4.539 & 11.750 & & .386 & .704 \\
\hline & $\begin{array}{l}\text { Jumlahibuhamil 20-35 } \\
\text { tahun (X1) }\end{array}$ & -.001 & .001 & -1.162 & -2.400 & .027 \\
\hline & $\begin{array}{l}\text { Jumlah bayi yang men- } \\
\text { dapatkan ASI full } 6 \text { bu- } \\
\text { lan dari ibu yang tidak } \\
\text { bekerja (X2) }\end{array}$ & .013 & .013 & .189 & 1.016 & .322 \\
\hline & $\begin{array}{l}\text { Kelainan dalam kandu- } \\
\text { ngan (X3) }\end{array}$ & .004 & .002 & 1.161 & 2.117 & .048 \\
\hline & $\begin{array}{l}\text { Bayi yang terdampak } \\
\text { gizi buruk pad ibu } \\
\text { hamil yang usia } 30-35 \\
\text { tahun (Y1) }\end{array}$ & .157 & .124 & .318 & 1.267 & .220 \\
\hline
\end{tabular}

a. Dependent Variable: Bayi yang meninggaldalamkandungan (Y2)

b. Pengujian secara parsial ( individu )

Hipotesis uji :

$\mathrm{H}_{0}=$ Tidak Signifikan

$\mathrm{H}_{\mathrm{a}}=$ Signifikansi

Hasil uji :

- Dari tabel sig. $\mathrm{X}_{1}$ terhadap $\mathrm{Y}_{2}$ adalah : 0.027. Nilai taraf sig 0.05 ( $\left.0.027>0.05\right)$ maka $\mathrm{H}_{0}$ 
ditolak dan $\mathrm{H}_{\mathrm{a}}$ diterima, artinya koefisien analisis jalurnya signifikan. Besarnya pengaruh $\mathrm{X}_{1}$ terhadap $\mathrm{Y}_{2}$ sebesar -1.162 .

- Dari tabelsig. $\mathrm{X}_{2}$ terhadap $\mathrm{Y}_{2}$ adalah : 0.322. Nilai taraf sig 0.05 ( $\left.0.322>0.05\right)$ maka $\mathrm{H}_{0}$ diterima dan $\mathrm{H}_{\mathrm{a}}$ ditolak, artinya koefisien analisis jalurnya tidak signifikan. Besarnya pengaruh $\mathrm{X}_{2}$ terhadap $\mathrm{Y}_{2}$ sebesar 0.189 .

- Dari tabelsig. $X_{3}$ terhadap $\mathrm{Y}_{2}$ adalah : 0.048. Nilai taraf sig 0.05 ( $\left.0.048>0.05\right)$ maka $\mathrm{H}_{0}$ ditolak dan $\mathrm{H}_{\mathrm{a}}$ diterima, artinya koefisien analisis jalurnya signifikan. Besarnya pengaruh $\mathrm{X}_{1}$ terhadap $\mathrm{Y}_{2}$ sebesar 1.161.

- Dari tabelsig. $X_{2}$ terhadap $Y_{2}$ adalah : 0.220. Nilai sig taraf sig 0.05 ( $\left.0.220>0.05\right)$ maka $\mathrm{H}_{0}$ diterima dan $\mathrm{H}_{\mathrm{a}}$ ditolak, artinya koefisien analisis jalurnya tidak signifikan. Besarnya pengaruh $\mathrm{X}_{2}$ terhadap $\mathrm{Y}_{2}$ sebesar 0.318 .

Dengan demikian, model kausal dua persamaan jalur dapat dilihat sebagai berikut:

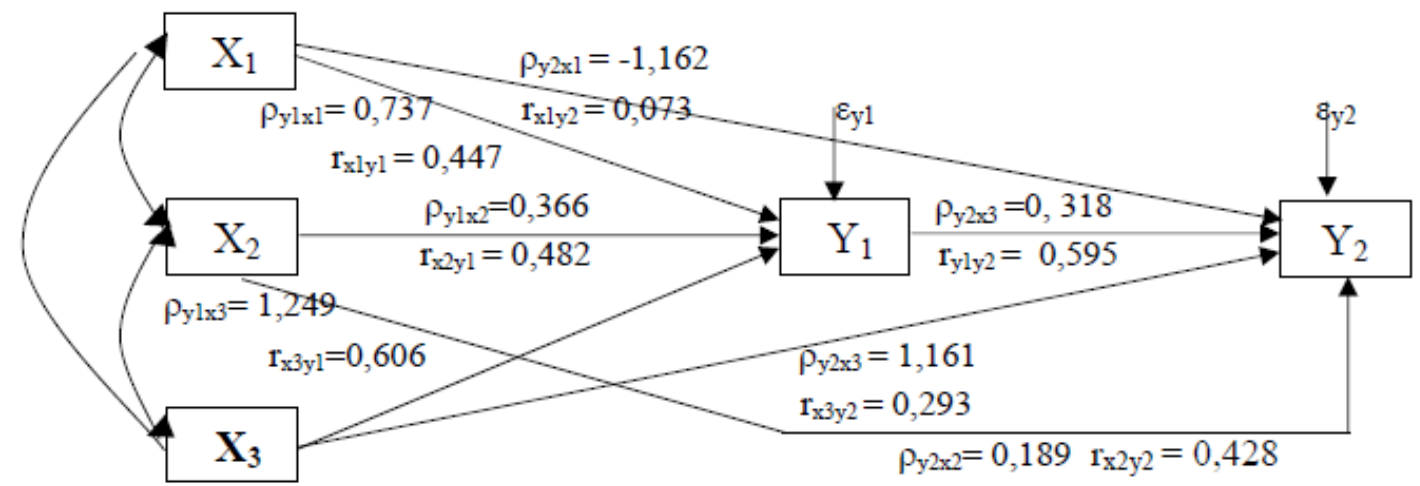

GAMBAR 4. Model kausal dua persamaan jalur Bayi yang meninggal dalam kandungan $\left(\mathrm{Y}_{2}\right)$, Bayi yang terdamapak gizi buruk pada ibu hamil yang usia 30-35 tahun ( $\left.\mathrm{Y}_{1}\right)$, Jumlah ibu hamil 20-35 tahun $\left(\mathrm{X}_{1}\right)$, Jumlah bayi yang mendapatkan ASI full 6 bulan dari ibu yang tidak bekerja $\left(\mathrm{X}_{2}\right)$ dan Kelainan dalam kandungan $\left(\mathrm{X}_{3}\right)$.

\section{KESIMPULAN}

Analisi jalur terhadap kematianbalita pada derajat kesehatan balita di Sulawesi Selatandengan model dua persamaan jalur, maka persamaan strukturalnya yaitu :

Model I : Y1 $=\rho_{\mathrm{y} 1 .} X_{1}+\rho_{\mathrm{y} 1 .} X_{2}+\rho_{\mathrm{y} 1 .} X_{3}+\varepsilon_{\mathrm{y} 1}$

$$
\hat{Y} 1=0,737 X_{1}+0,366 X_{2}+1,249 X_{3}
$$

Model II : $\mathrm{Y} 2=\rho_{\mathrm{y} 2 .} \mathrm{X}_{1}+\rho_{\mathrm{y} 2 .} \mathrm{X}_{2}+\rho_{\mathrm{y} 2 .} \mathrm{X}_{3}+\rho_{\mathrm{y} 2 .} \mathrm{Y}_{1}+\varepsilon_{\mathrm{y} 2}$

$$
\hat{\mathrm{Y}} 2=1,162 \mathrm{X}_{1}+0,189 \mathrm{X}_{2}+1,161 \mathrm{X}_{3}+0,318 \mathrm{Y}_{1}
$$

a. Pengaruh langsung

- Pengaruh jumlah ibu hamil 20-35 tahun $\left(X_{1}\right)$ terhadap bayi yang meninggal dalam kandungan $\left(\mathrm{Y}_{2}\right)$ dengan koefisien analisis jalurnya sebesar -1.162

- Pengaruh jumlah bayi yang mendapatkan ASI full 6 bulan dari ibu yang tidak bekerja $\left(\mathrm{X}_{2}\right)$ terhadap bayi yang meninggal dalam kandungan $\left(\mathrm{Y}_{2}\right)$ dengan koefisien analisis jalurnya sebesar 0.189

- Pengaruh kelainan dalam kandungan $\left(\mathrm{X}_{3}\right)$ terhadap Bayi yang meninggal dalam kandungan $\left(\mathrm{Y}_{2}\right)$ dengan koefisien analisis jalurnya sebesar 1.161

- Pengaruh bayi yang terdampak gizi buruk pada ibu hamil yang usia 30-35 tahun ( $\left.\mathrm{Y}_{1}\right)$ terhadap bayi yang meninggal dalam kandungan $\left(\mathrm{Y}_{2}\right)$ dengan koefisien analisis jalurnya sebesar 0.318

b. Pengaruh tidak langsung

- Pengaruh jumlah ibu hamil 20-35 tahun $\left(X_{1}\right)$ terhadap bayi yang meninggal dalam kandungan $\left(\mathrm{Y}_{2}\right)$ melalui bayi yang terdampak gizi buruk pada ibu hamil yang usia 30- 35 
tahun $\left(\mathrm{Y}_{1}\right)$ dengan koefisien analisis jalurnya sebesar 0.234

- Pengaruh jumlah bayi yang mendapatkan ASI full 6 bulan dari ibu yang tidak bekerja $\left(\mathrm{X}_{2}\right)$ terhadap bayi yang meninggal dalam kandungan $\left(\mathrm{Y}_{2}\right)$ melalui bayi yang terdampak gizi buruk pada ibu hamil yang usia 30-35 tahun $\left(\mathrm{Y}_{1}\right)$ dengan koefisien analisis jalurnya sebesar 0.116

- Pengaruh kelainan dalam kandungan $\left(\mathrm{X}_{3}\right)$ terhadap bayi yang meninggal dalam kandungan $\left(\mathrm{Y}_{2}\right)$ melalui bayi yang terdampak gizi buruk pada ibu hamil yang usia 30- 35 tahun $\left(\mathrm{Y}_{1}\right)$ dengan koefisien analisis jalurnya sebesar 0.397

\section{DAFTAR PUSTAKA}

Asdar., Badrullah, \& Jeranah. (2016). Regresi, Analisis Jalur Dan SEM. Makassar: Kretakupa Makassar

Adminbka. (2013). Pengertian ASI Eksklusif. http://botolkacaasi.com/pengertian-asi-eksklusif. Diakses tanggal 8 mei 2013.

B. Sutomo. (2010). Menu Sehat Alami Untuk Balita. Jakarta: Demedia

Hello Sehat. (2016). Kehamilan kandungan keuntungan dan resiko di berbagai usia saat hamil. https://hellosehat.com/kehamilan/kandungan/keuntungan-dan-risiko-di-berbagai-usiasaat-hamil/. Diakses tanggal 21 juli 2016

Ilmu Psikologi. (2012). Pengertian Kesehata https://belajarpsikologi.com/pengertian-kesehatan/. Diakses tanggal 16 Januari 2012.

Kuncoro. E.A dan Riduan. (2007). Cara Menggunakan dan Memakai Analisis Jalur (Path Analysis), Bandung: Alfabeta

Sugiyono. (2009). Statistik Untuk Penelitian. Bandung: Alfabeta.

Sarwono, J. (2007). Analisis Jalur untuk Riset Bisnis dengan SPSS, Andy, Yogyakarta. Soekidjo Notoatmodjo. (2007). Kesehatan Masyarakat, Ilmu \& Seni. Jakarta: Rineka Cipta. Tiro, M. A., Sukarna, \& Aswi. (2010). Analisis Jalur. Makassar: Andira Publisher Makassar. 